\title{
Mars orbiter ready to scout for future landing sites as NASA looks ahead
}

With two healthy rovers still roaming the martian surface 19 months after they landed, NASA is set to take the next step in Mars exploration by sending its largest orbiter to the planet since the 1970s. The \$500-million Mars Reconnaissance Orbiter (MRO), due to launch from Cape Canaveral, Florida, on 10 August, may also signal a new period of stability for the agency's Mars programme. After recent budget scares and shifts in priorities, the programme looks to be on track to send more advanced rovers to the planet over the next decade.

After it arrives in March next year, the MRO will spend eight months settling into its final 320 -kilometre orbit. From there it will point six instruments at the planet's surface, including a spectrometer for identifying minerals, a sounding radar for locating subsurface water (see Nature 435, 266-267; 2005), and a camera sharp enough to resolve objects the size of a kitchen table. The camera will increase highresolution coverage of the planet from $2 \%$ to $20 \%$, and allow Mars planners to scout for future landing sites.

The MRO will be followed in 2007 by the Phoenix lander, designed to search for water and organic molecules around the planet's north pole. Then in 2009 the most ambitious mission in the queue, the mobile Mars Science Laboratory (MSL), will launch. With a price tag of at least $\$ 1$ billion, the MSL will travel a kilometre or more from its landing site carrying a suite of sophisticated instruments for sniffing out chemical evidence of life.

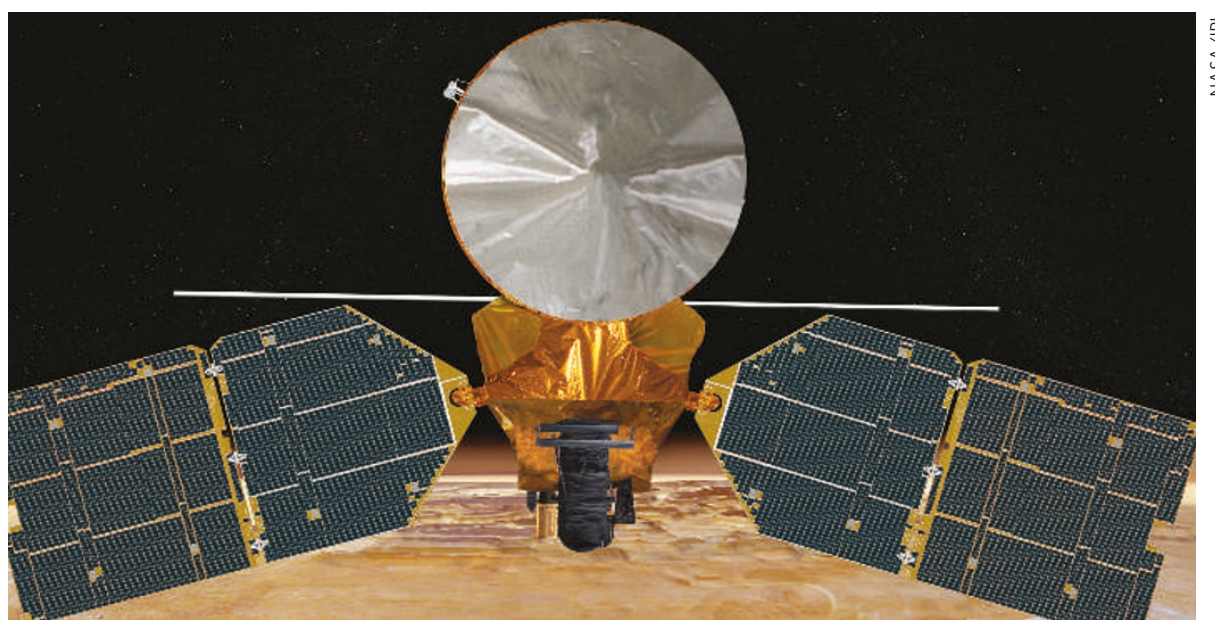

The Mars Reconnaissance Orbiter will analyse conditions on the red planet in unparalleled detail.

This spring, the MSL was in serious danger of having its launch date slip two years or more as NASA struggled to contain rising costs. But the situation has improved, and the mission remains targeted for 2009, says Mars programme director Douglas McCuistion. This reprieve is partly due to a decision to defer missions that will pave the way for astronauts to visit Mars around 2030. McCuistion says that launching two MSLs, which science advisory groups have recommended partly as insurance against a launch failure, is "not impossible" but depends on future NASA funding levels.

The money crunch has also eased with NASA's decision to cancel the 2009 Mars

\section{NASA'S FUTURE MARS MISSIONS}

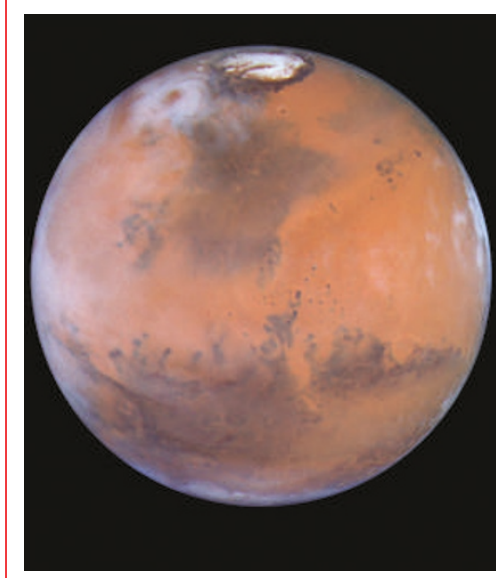

10 August 2005: Mars Reconnaissance Orbiter Will make high-resolution measurements of the surface from orbit after its arrival in March 2006.

\section{Late 2007: Phoenix lander}

Will search for water and organic molecules in the

high-northern latitudes of Mars.

\section{Late 2009: Mars Science Laboratory}

A science lab on a mobile rover. Will look for signs of life, as well as studying local geology and planetary processes relevant to prospects for life.

\section{0+: Future missions}

Plans include at least one Mars Scout mission and possible sample-return missions, although there are no set dates. Work is planned to develop miniaturized surface-science instruments and the ability to drill 100 metres below the surface. Still aiming for a manned mission around 2030.
Telecommunications Orbiter, which would have acted as a high-speed data relay for other Mars spacecraft. McCuistion says the MRO and other spacecraft already orbiting the planet will serve as data relays instead.

\section{Bringing samples home}

The new Mars plan retains a sample-return mission as a goal, but it has an unspecified launch time. University of Colorado planetary scientist Bruce Jakosky, who until recently chaired NASA's outside advisory group for Mars exploration, says there are "legitimate differences of opinion" about where sample return should fit in the mission queue. Most scientists still consider bringing Mars samples back to Earth a priority, says Arizona State University planetary scientist Ron Greeley, as the rocks must be dated isotopically in a lab to sort out the planet's complicated geological history.

But bringing samples home will be difficult and expensive. And new, more stringent recommendations from the National Academy of Sciences for sterilizing Mars-bound spacecraft, to protect against biological contamination of the planet, could drive up the cost even more.

Yet NASA's long-term plan to send astronauts to Mars could ultimately work in favour of sample return, as engineers will need to understand how surface materials behave and what risks they might pose. Says Greeley: "I'd be surprised if we didn't have sample return as a precursor to humans for safety reasons." Tony Reichhardt 